\title{
Formation and effect of topologically close-packed phases in nickel-base superalloys
}

\author{
A. S. Wilson* \\ Department of Materials Science \& Metallurgy, University of Cambridge, \\ 27 Charles Babbage Road, Cambridge CB3 0FS \\ * Corresponding author, email asw33@cam.ac.uk. 01223331950.
}

\begin{abstract}
The formation of topologically close-packed (TCP) phases in nickel-base superalloys is an issue of increasing importance as alloys are designed with higher refractory element contents to meet the requirements of next generation turbine engines. This review considers the factors that affect an alloy's susceptibility to TCP formation. In particular, the debate surrounding the effect of certain individual elements, such as Co and Re, in promoting or suppressing TCP formation is examined alongside the various mechanisms that have been proposed to account for this behaviour. In addition, the detrimental effects of these phases on the alloy's mechanical properties are discussed, including crack initiation at precipitates, depletion of solid solution strengthening refractory elements and the effect on $\gamma / \gamma^{\prime}$ rafting behaviour.
\end{abstract}

Keywords: nickel-base superalloys, topologically close-packed phases, sigma phase, mu phase, laves phase

\section{Introduction}

Nickel-base superalloys are used for the components in the gas turbine engine that experience the most demanding conditions of high temperature and load because they have exceptional mechanical properties at high temperatures. In particular, Nibase superalloys are used for turbine discs and blades but the conditions experienced by these two components are somewhat different. Turbine blades experience the highest temperatures and therefore utilise alloys optimised for use as single crystals in order to provide the best creep and fatigue properties. The operating temperatures for turbine discs are considerably lower but they experience higher stresses. As a result, polycrystalline alloys are used which require a combination of high yield strength and fracture toughness. In addition, resistance to fatigue crack growth and sufficient creep resistance are required particularly at the rim which experiences higher temperature than the bore, although the creep requirements are less stringent than for blades.

The microstructure of a Ni-base superalloy is based on two main phases: the gamma $(\gamma)$ phase, a FCC nickel-base matrix phase, and the gamma prime $\left(\gamma^{\prime}\right)$ phase, a superlattice structure of FCC. The total volume fraction and size distribution of $\gamma^{\prime}$ vary depending on the alloy's composition and processing and both affect the strength of the alloy. The volume fraction of $\gamma$ ' present in alloys used for turbine blades is considerably higher $(\sim 70 \%)$ than that in alloys used for turbine discs ( 40 - 
$55 \%)^{1}$. Gamma double prime $\left(\gamma^{\prime \prime}\right)$ is formed preferentially as an alternative strengthening phase to $\gamma^{\prime}$ in certain superalloys, which are based on the $\mathrm{Ni}-\mathrm{Fe}$ system or rich in $\mathrm{Nb}$, but this review is concerned solely with $\gamma^{\prime}$-forming superalloys.

Environmental targets for reduction of emissions from aircraft mean that future generations of aeroengines will be required to operate with higher thermal efficiencies. This necessitates the design of new Ni-base superalloys with the capability to operate at higher temperatures. To meet these requirements increased refractory element contents are required for solid solution strengthening. In addition, the $\mathrm{Cr}$ content must be sufficient to provide environmental resistance. This is particularly important for disc alloys, which, unlike blades, are not commonly coated at this time so rely on the environmental resistance of the alloy. However, high concentrations of these elements promote the formation of topologically closepacked (TCP) phases following prolonged periods of high temperature exposure during service.

TCP phases are intermetallic phases that can be detrimental to the mechanical properties of the superalloy. Therefore, an understanding of the occurrence of TCP formation is key to the design and development of new Ni-base superalloys with optimised compositions to fulfil these competing requirements.

This review focuses on two key aspects of understanding TCPs in Ni-base superalloys: the different factors affecting the propensity of a given alloy to precipitate TCP phases and the effect of these phases on the alloy's mechanical properties. A previous review of TCP phases by Sun and Zhang ${ }^{2}$ concentrated on mechanisms of precipitation, the structure and morphology of TCP phases and the effect of certain elements on formation in primarily single-crystal superalloys. This review focuses instead on a broader review of the literature concerning factors that affect TCP formation and their effect.

A large proportion of the literature available on TCP phases in Ni-base superalloys concerns single crystal alloys for turbine blade applications. This is because high refractory element contents combined with high $\gamma^{\prime}$ volume fractions concentrate the refractory elements in the $\gamma$ phase, making them susceptible to TCP formation. Literature concerning TCP phases in polycrystalline alloys is less common; however, more recent requirements for higher refractory element contents and $\gamma^{\prime}$ volume fractions in disc alloys have led to an increased interest in this area. As a result, this review is concerned with both single-crystal and polycrystalline alloys.

\section{TCP phases}

TCP phases have several distinctive crystallographic characteristics: the presence of solely tetrahedral interstices, resulting in a high and uniform atomic packing density (although there are a variety of sizes of component atoms) and complex crystal structures of Kasper co-ordination polyhedra. ${ }^{3}$ The TCP phases that are commonly observed in Ni-base superalloys are summarised in Table 1. The stoichiometric 
compositions given here are only ideal compositions and many of these phases have wide ranges of stoichiometry, e.g. $\sigma$ and $\mu{ }^{1}$ TCP phases are commonly precipitated following long-term thermal exposure at high temperatures; however, in certain superalloys they can be formed during solidification. ${ }^{4}$ Kinetic considerations are such that TCP phases tend to form in a restricted temperature range that is below the relevant solvus but high enough that precipitation will occur within a reasonable time period. These precipitates can display a wide variety of different morphologies, some examples of which are shown in Fig. 1.

\begin{tabular}{|l|l|l|l|l|}
\hline Phase & $\begin{array}{l}\text { Stoichiometric } \\
\text { composition }\end{array}$ & Unit cell type & $\begin{array}{l}\text { Space } \\
\text { group }\end{array}$ & Lattice parameters \\
\hline$\mu$ & $\mathrm{A}_{6} \mathrm{~B}_{7}$ & Rhombohedral & $\begin{array}{l}166 . \mathrm{R}- \\
3 \mathrm{M}\end{array}$ & $\begin{array}{l}\mathrm{a}=\mathrm{b}=0.4755 \mathrm{~nm} \\
\mathrm{c}=2.583 \mathrm{~nm}\end{array}$ \\
\hline $\mathrm{P}$ & $\begin{array}{l}\text { e.g. } \\
\mathrm{Cr}_{18} \mathrm{Mo}_{42} \mathrm{Ni}_{40}\end{array}$ & $\begin{array}{l}\text { Primitive } \\
\text { orthorhombic }\end{array}$ & $62 . \mathrm{Pbnm}$ & $\begin{array}{l}\mathrm{a}=1.698 \mathrm{~nm} \mathrm{~b}=0.475 \mathrm{~nm} \\
\mathrm{c}=0.907 \mathrm{~nm}\end{array}$ \\
\hline $\mathrm{R}$ & $\begin{array}{l}\text { e.g. } \\
\mathrm{Cr}_{18} \mathrm{Mo}_{31} \mathrm{Co}_{51}\end{array}$ & Rhombohedral & $148 . \mathrm{R}-3$ & $\begin{array}{l}\mathrm{a}=\mathrm{b}=1.093 \mathrm{~nm} \\
\mathrm{c}=1.934 \mathrm{~nm}\end{array}$ \\
\hline$\sigma$ & $\mathrm{A}_{2} \mathrm{~B}$ & Tetragonal & $\begin{array}{l}136 . \\
\mathrm{P} 42 / \mathrm{mnm}\end{array}$ & $\begin{array}{l}\mathrm{a}=\mathrm{b}=0.878 \mathrm{~nm} \\
\mathrm{c}=0.454 \mathrm{~nm}\end{array}$ \\
\hline \multirow{2}{*}{ Laves } & $\mathrm{AB}_{2}$ & $\begin{array}{l}\text { Hexagonal } \\
\text { (C14 and C36) }\end{array}$ & $\begin{array}{l}194 . \\
\mathrm{P} 63 / \mathrm{mmc}\end{array}$ & $\begin{array}{l}\mathrm{a}=\mathrm{b}=0.475-0.495 \mathrm{~nm} \\
\mathrm{c}=0.77-0.815 \mathrm{~nm}\end{array}$ \\
\cline { 2 - 5 } & & $\begin{array}{l}\text { Cubic } \\
\text { (C15) }\end{array}$ & $\begin{array}{l}227 . \\
\mathrm{Fd} 3 \mathrm{~m}\end{array}$ & \\
\hline
\end{tabular}

Table 1. TCP phases in nickel-base superalloys.,3,5
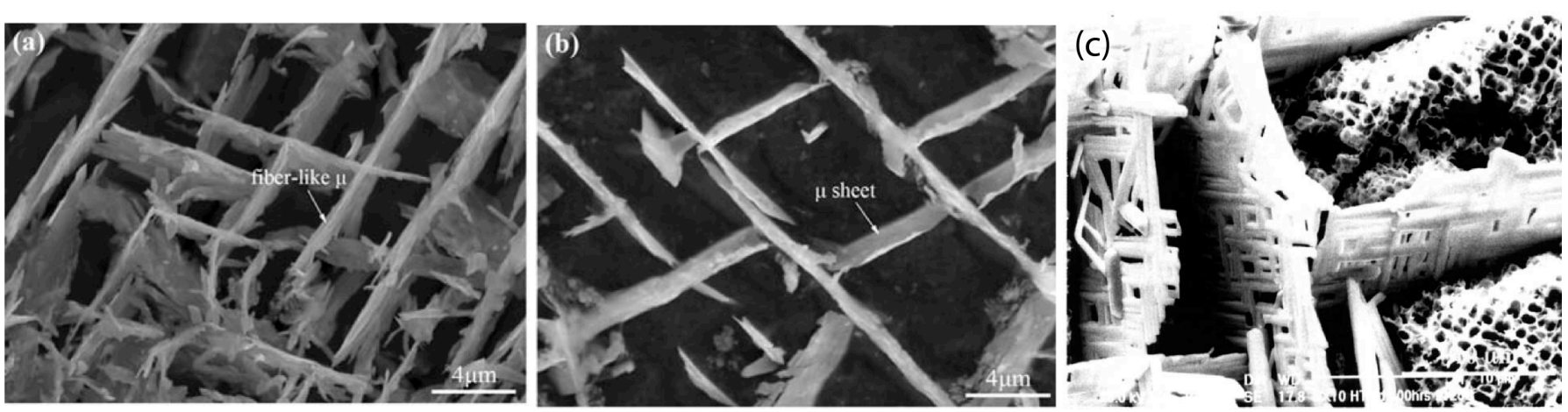

Fig. 1. (a) $\mu$ fibres in $\mathrm{K} 446$ alloy after $3000 \mathrm{~h}$ at $850^{\circ} \mathrm{C}^{6}$, (b) $\mu$ sheets in $\mathrm{K} 446$ alloy after $1000 \mathrm{~h}$ at $800^{\circ} \mathrm{C}^{7}$, (c) TCPs with basket-weave morphology in SX-2 alloy after $100 \mathrm{~h}$ at $1125^{\circ} \mathrm{C}^{8}$. Reproduced with permission from Springer (a \& b) and Elsevier (c). 


\section{Factors affecting the precipitation of TCP phases}

\subsection{Effect of individual elements}

All elements in Ni-base superalloys have a tendency to partition either to the $\gamma$ phase or the $\gamma^{\prime}$ phase or equally between the two. This tendency is described by the partitioning ratio, which is defined as:

$$
k_{i}=\frac{X_{i \gamma}}{X_{i \gamma^{\prime}}}
$$

Where $\mathrm{k}_{i}$ is the partitioning ratio for element $\mathrm{i}, \mathrm{X}_{i}$ is the concentration of element $\mathrm{i}$ in the relevant phase.

Many studies have been carried out to measure the partitioning ratios of component elements in different alloys. These vary to an extent between alloys and an example is shown in Fig. 2. $\gamma$-partitioning elements are illustrated on the right of the graph and $\gamma^{\prime}$-partitioning elements on the left. The distance which the graph extends from $\mathrm{K}_{\mathrm{i}}=1$ illustrates the strength of that element's partitioning behaviour. Knowledge of the standard partitioning behaviour of these elements is key to understanding their effect on TCP phase precipitation because TCP phases precipitate from the $\gamma$ phase and thus the partitioning behaviour affects their tendency to precipitate.

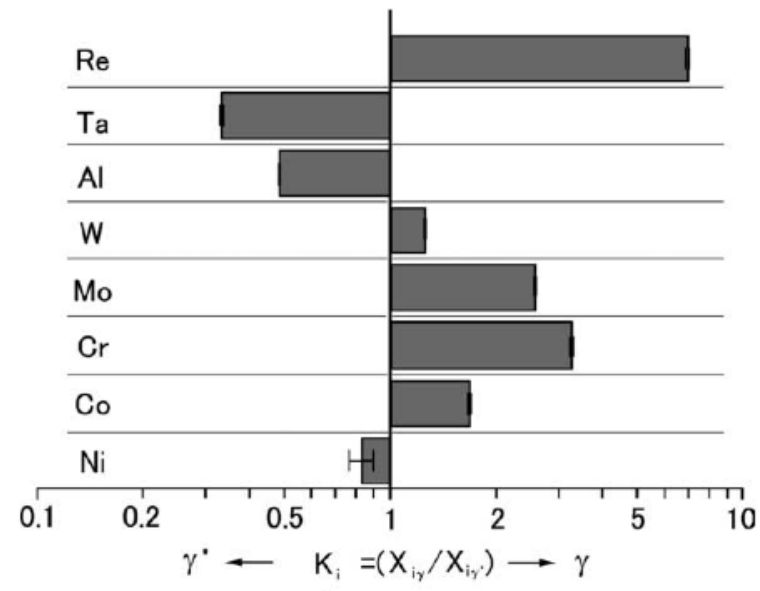

Fig. 2. $\gamma / \gamma^{\prime}$ partitioning behaviour of elements in TMS-75 at $1373 \mathrm{~K}^{9}$. Reproduced with permission from Elsevier.

Al and Ti: It is well known that increasing the Al+Ti content of an alloy will increase the $\gamma^{\prime}$ volume fraction and, thus, increase the susceptibility of the alloy to TCP formation by concentrating the $\gamma$-partitioning TCP-forming elements in the $\gamma$ phase. The potency of this effect was shown by Dreshfield and Ashbrook ${ }^{10}$ who reported that an increase of $1 \mathrm{wt} . \% \mathrm{Al}+\mathrm{Ti}$ changed IN100 from $\sigma$-free after 5000 hours at $843^{\circ} \mathrm{C}$ to $\sigma$-containing after 24 hours at $843^{\circ} \mathrm{C}$. In addition, Ti causes the partitioning ratios of elements including $\mathrm{Mo}, \mathrm{Cr}, \mathrm{W}$, and particularly $\mathrm{Re}$, to increase ${ }^{11}$. This further 
promotes TCP formation by increasing the concentration of TCP-forming elements in the $\gamma$ phase.

Ta: Ta promotes $\gamma^{\prime}$ formation and, as such, has been shown to have a similar effect to $\mathrm{Al}$ and Ti of promoting TCP formation by increasing the concentration of TCPforming elements in the $\gamma$ phase. ${ }^{12}$ In addition, it has been shown that Ta also increases the partitioning ratios of both $\mathrm{W}^{13}$ and $\mathrm{Cr}^{14}$ by displacing these atoms from the $\gamma^{\prime}$ phase, again promoting TCP formation.

Co: The exact role that Co plays in TCP formation remains unclear. Various studies have shown that higher Co levels improve microstructural stability but several different explanations for this phenomenon have been proposed. The first proposed explanation is that Co alters the $\gamma / \gamma^{\prime}$ partitioning behaviour of other elements resulting in a reduced concentration of TCP-forming elements in the $\gamma$ phase. ${ }^{15,16}$ It is suggested that this can also cause a change in the lattice parameter of the $\gamma$ phase leading to a lattice misfit with the TCP phases which is less favourable to precipitation. ${ }^{5}$ However, whilst reducing the partitioning of TCP-forming elements to the $\gamma$ phase, Wang et al. ${ }^{17}$ observed that increasing the Co content can additionally lead to an increase in the $\gamma^{\prime}$ volume fraction as $\gamma^{\prime}$-forming elements are also rejected from the matrix. Despite this, a decrease in TCP precipitation with higher Co content was still observed, which they proposed could be attributed to a more potent effect of Co increasing the diffusion of other elements and, hence, reducing the segregation that otherwise promotes TCP precipitation in single crystal alloys.

Cui et al. ${ }^{18}$ and Jones et al. ${ }^{19}$ investigated the effect of increasing Co and $\mathrm{Ti}$ simultaneously in polycrystalline disc alloy compositions and appeared to observe opposing effects of TCP suppression and promotion respectively. In fact, Cui et al. ${ }^{14}$ concluded that their observed decrease in $\sigma$ formation could be attributed primarily to the reduction in Cr content caused by alloying with Co-16.9 wt.\% Ti so no conclusions about the effect of Co could be drawn. Jones et al. ${ }^{19}$ proposed that, alongside the known effect of Ti in increasing TCP precipitation, Co contributes by displacing $\mathrm{Cr}$ from the $\gamma^{\prime}$ phase into the $\gamma$ phase. However, investigation of a further alloy by Minshull ${ }^{20}$, alongside those discussed by Jones et al. ${ }^{19}$, which contained the same Ti content but no increase in the Co content, revealed a greater susceptibility to $\sigma$ precipitation than when the Co was also increased. This suggests that it is the increase in Ti content that primarily promotes TCP precipitation in these alloys and that the Co may be having a suppressant effect as expected. Although it still does not account for the observed increase in $\sigma$ precipitation between two alloys where only the Co content is increased therefore further investigation is required to evaluate this phenomenon.

In addition, it is proposed that the Co concentration affects which type of TCP phase is formed. Co appears in high concentrations in the $\mu$ phase and hence it is proposed that it promotes the formation of $\mu$ in preference to $\sigma .{ }^{5,21}$ However, $\mu$ has often been observed to precipitate after, and at the expense of, metastable $\sigma$ and hence there is speculation that a preference for $\mu$ formation may increase the incubation period of an alloy before any TCP phases form. ${ }^{5}$

Therefore, the available literature can be interpreted as presenting a convincing case for a reduction in the susceptibility to TCP precipitation with increasing Co levels, 
with the exception of the work by Jones et al. ${ }^{19}$ which needs further investigation. However, the mechanism(s) for this reduction have not been satisfactorily explained.

Cr: The role of $\mathrm{Cr}$ content in promoting TCP formation is two-fold: it contributes directly to TCP formation (this is most pronounced for TCPs with a high Cr content such as $\sigma$ ) and also changes the partitioning behaviour of other TCP-forming elements. The $\gamma / \gamma^{\prime}$ partitioning ratios of certain TCP-forming elements, particularly $\mathrm{Re}$, in addition to $\mathrm{Cr}$ itself, have been consistently observed to increase with $\mathrm{Cr}$ content. ${ }^{22,23}$ In contrast, the partitioning ratios of certain other elements, including $\mathrm{W}, \mathrm{Co}$ and Mo, have been seen to increase in some alloys ${ }^{23}$ but not in others ${ }^{22}$.

Mo and W: Both Mo and W are TCP-forming elements. In a study by Kirby et al. ${ }^{24}$ it was shown that Mo and $W$ are around 1.5-2 times as effective as $\sigma$-formers compared with $\mathrm{Cr}$ in terms of the additional volume fraction of $\sigma$ formed for a given increase in at.\%. W has also been shown to preferentially promote precipitation of $\mathrm{P}$ phase. ${ }^{5}$

Re: Re has been included in single crystal alloys since the second-generation of alloys for turbine blades due to its effectiveness as a solid solution strengthener ${ }^{1}$ but its potency in promoting TCP formation has been shown in many studies. ${ }^{12,25,26}$ This is exacerbated by its slow diffusion rate through the matrix which makes it impractical to solution heat treat alloys for long enough to fully remove the remnant dendritic segregation. Hence, TCP phases in Re-containing alloys form primarily in the dendrite cores. In addition, these phases can have very high Re contents; for example, $\mathrm{P}$ phase was found by Walston et al. to contain nearly $50 \% \mathrm{Re}^{27}$

$\mathbf{R u}$ : It is well established that the addition of Ru to single crystal alloys with high refractory element contents (particularly of Re) reduces the tendency for TCP precipitation. However, the exact mechanism by which this occurs remains a matter for debate. Initial investigations attributed it to the so-called "reverse partitioning effect" 28 by which the presence of Ru decreases the partitioning ratio of usually $\gamma$ partitioning refractory elements whilst increasing the partitioning ratio of $\gamma^{\prime}-$ partitioning elements. This idea has been repeated by various authors who have observed a change in the $\gamma / \gamma^{\prime}$ partitioning ratios in particular alloy systems. ${ }^{15,29,30}$ However, other studies have shown no evidence of reverse partitioning in different alloy systems. ${ }^{31-35}$

Fig. 3 summarises the observed effect of the addition of $\mathrm{Ru}$ on the $\gamma / \gamma^{\prime}$ partitioning behavior of $\mathrm{Al}, \mathrm{W}$ and $\mathrm{Re}$ in a variety of alloys, the majority of which were amongst those that showed evidence of reverse partitioning. It can be seen that the size of the measured effect varies significantly between different alloys and does not scale with the size of the Ru addition. A small change in composition of the alloy can significantly change the magnitude of the effect, for example the observed effect for 0.96 at.\% $\mathrm{Ru}$ addition and 0.97 at.\% addition from Walston et al. ${ }^{15}$ varies significantly although the alloy compositions only differ by an addition of $0.1 \mathrm{wt} . \%$ $\mathrm{W}$ and $1 \mathrm{wt}$.\% Re. Fig. 3 also illustrates that the interpretation of the significance of observed results varies in the literature; for example, Han et al. ${ }^{30}$ concluded that there was evidence for reverse partitioning on addition of 1.49 at.\% Ru to their alloy, 
whereas Reed et al. ${ }^{31}$ concluded that there was no evidence on addition of 1.26 at.\% $\mathrm{Ru}$ to a different alloy. This is reflected by the relative behaviour of the $\mathrm{Al}$ partitioning ratios but, when considering $\gamma$-partitioning elements, the relative change in the $\mathrm{W}$ and Re ratios suggests that the former are ascribing greater significance to a similar magnitude of change than the latter. It is worth considering also the variation in techniques used to measure the compositions in each of these investigations, from inductively-coupled plasma spectroscopy after extraction of the $\gamma^{\prime 30}$ to atom probe tomography ${ }^{31}$. The different levels of accuracy inherent in these techniques may explain some of the variation displayed in Fig. 3. Despite these areas of disagreement, it is generally accepted that the addition of Ru does not change the type of TCP phases that form or significantly alter their composition. ${ }^{35,36}$

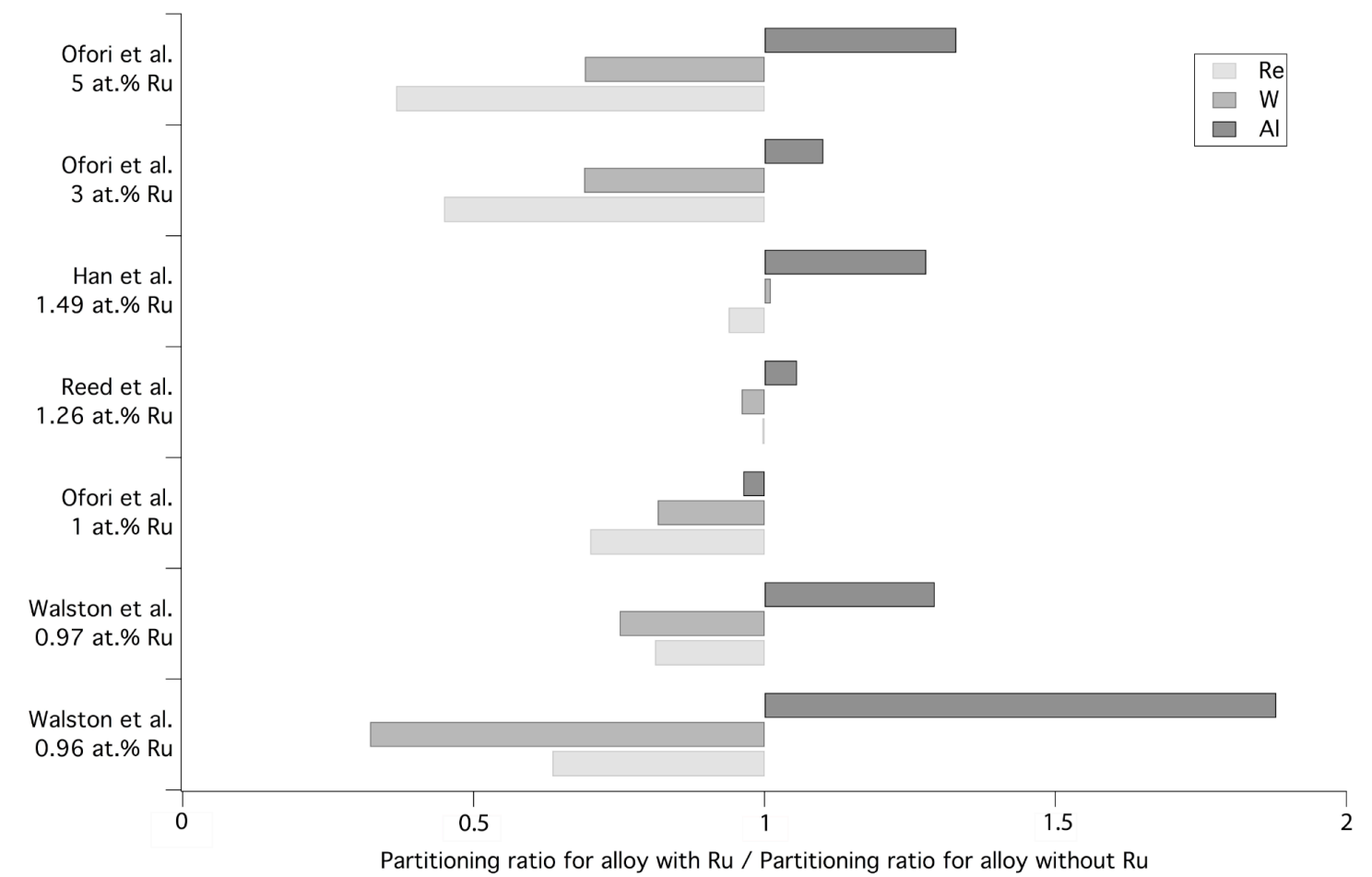

Fig. 3. Effect of Ru additions on $\gamma / \gamma^{\prime}$ partitioning ratios of $\mathrm{Al}, \mathrm{W}$ and Re in a variety of alloys. Data taken from Walston et al. ${ }^{27}$, Ofori et al. ${ }^{29}$, Han et al. ${ }^{30}$ and Reed et al. ${ }^{31}$

Other proposed mechanisms for TCP suppression include: the destabilisation of $\gamma^{\prime}$ at higher temperatures such that the resulting lower volume fraction of $\gamma^{\prime}$ leads to a reduced supersaturation of TCP-forming elements in the $\gamma^{35}$; alteration of the TCPmatrix interface to have a lower density of ledges contributing to a lower growth rate and a difference in precipitate morphology ${ }^{35}$; increased solubility of Re in the $\gamma$ phase caused by the presence of $\mathrm{Ru}^{34,36}$.

The aforementioned factors affect either the nucleation or growth rate of TCP precipitates and it is often not clear which of these $\mathrm{Ru}$ is affecting more.

Matuszewski et al. ${ }^{37}$ observed the primary effect of Ru in the alloys they investigated to be on nucleation due to a reduction in the driving force for nucleation and an increase in the strain energy associated with the $\sigma / \gamma$ lattice misfit.

In contrast to the previously mentioned suppressant effect, it has been observed that, in some high $\operatorname{Cr}(>5 \mathrm{wt} . \%)$ alloys the addition of Ru can instead cause an 
increase in TCP precipitation. ${ }^{38,39}$ Once again, the mechanism behind this is not clear. Chen et al. ${ }^{38}$ attributed it to an increase in the partitioning of $\mathrm{Re}$ and $\mathrm{Cr}$ to the $\gamma$ phase, whereas Lv et al. ${ }^{39}$ observed reverse partitioning of $\mathrm{Cr}$ and $\mathrm{Co}$ and attributed the increase in TCP precipitation to Ru causing an increase of the diffusion coefficients of TCP-forming elements. However, the former investigated alloys containing $\sim 5.5 \mathrm{wt} . \% \mathrm{Cr}$ and $\sim 5 \mathrm{wt}$. $\% \mathrm{Ru}$ whilst the latter used alloys containing $\sim 9$ wt.\% $\mathrm{Cr}$ and $\sim 3$ wt.\% Ru. Hence, there may be an interaction effect between these elements that is dependent on their relative concentrations. It is clear that the composition of the alloy is crucial in determining the effect of Ru on TCP formation and the mechanisms by which this occurs.

It should be noted that the majority of single crystal alloy compositions investigated precipitate predominantly $\mathrm{P}$ or $\mathrm{R}$, sometimes concurrently with $\sigma$ or with $\sigma$ as a precursor. Cui et al. ${ }^{33}$ investigated whether any similar effect on TCP precipitation could be observed on addition of $\mathrm{Ru}$ to a disc alloy composition that precipitated only $\sigma$; no observable effect was found.

C: There are two aspects of the effect of $\mathrm{C}$ on TCP formation that will be considered here: the effect on segregation in single crystal alloys and the relationship between TCP phases and carbides.

In single crystal alloys TCP formation is promoted by the presence of severe segregation as previously mentioned. Importantly, there is no clear consensus in the literature as to whether the presence of $\mathrm{C}$ increases or reduces this segregation. In general, a reduction in the segregation of certain elements with the addition of $\mathrm{C}$ has been reported..$^{8,40-43}$ However, unlike the rest of these studies, Li et al. ${ }^{42}$ only observed a reduction in segregation of Re and W, not of Ta. Reduced segregation of TCP-forming elements is expected to result in a reduction of the TCP formation rate and this was confirmed by Tin and Pollock ${ }^{8}$. In contrast to these results, Al-Jarba and Fuchs ${ }^{44}$ observed no systematic variation in segregation with increasing $C$ content in a model single crystal alloy, whereas others observed an increase. ${ }^{45,46}$ The expected effect of increased segregation is an increase in the TCP formation rate. ${ }^{45}$ However, Kong and Chen observed a decrease in TCP formation rate in RR2086 despite an increase in segregation, due to the competing effect of $\mathrm{M}_{23} \mathrm{C}_{6}$ formation removing TCP-forming elements. Therefore, the effect of $\mathrm{C}$ on segregation varies between alloys, depending, amongst other factors, on the tendency of the alloy to form $\mathrm{M}_{23} \mathrm{C}_{6}$ carbides, as explained further below, and thus a clear conclusion cannot be drawn at this stage.

The second way in which $\mathrm{C}$ content affects TCP formation is the relationship between TCP phases and carbides. The direct competition for elements between $\sigma$ and $\mathrm{M}_{23} \mathrm{C}_{6}$ is well-established, ${ }^{47,48}$ since both phases are rich in $\mathrm{Cr}$ and other refractory elements. As a result, it has been shown that the presence of $\sigma$ reduces the formation rate of $\mathrm{M}_{23} \mathrm{C}_{6}$ and vice versa ${ }^{48}$. This was shown in the work of Lee et al. ${ }^{48}$, Fig. 4, where the wt.\% of $\mathrm{M}_{23} \mathrm{C}_{6}$ is lower when $\sigma$ is formed. 

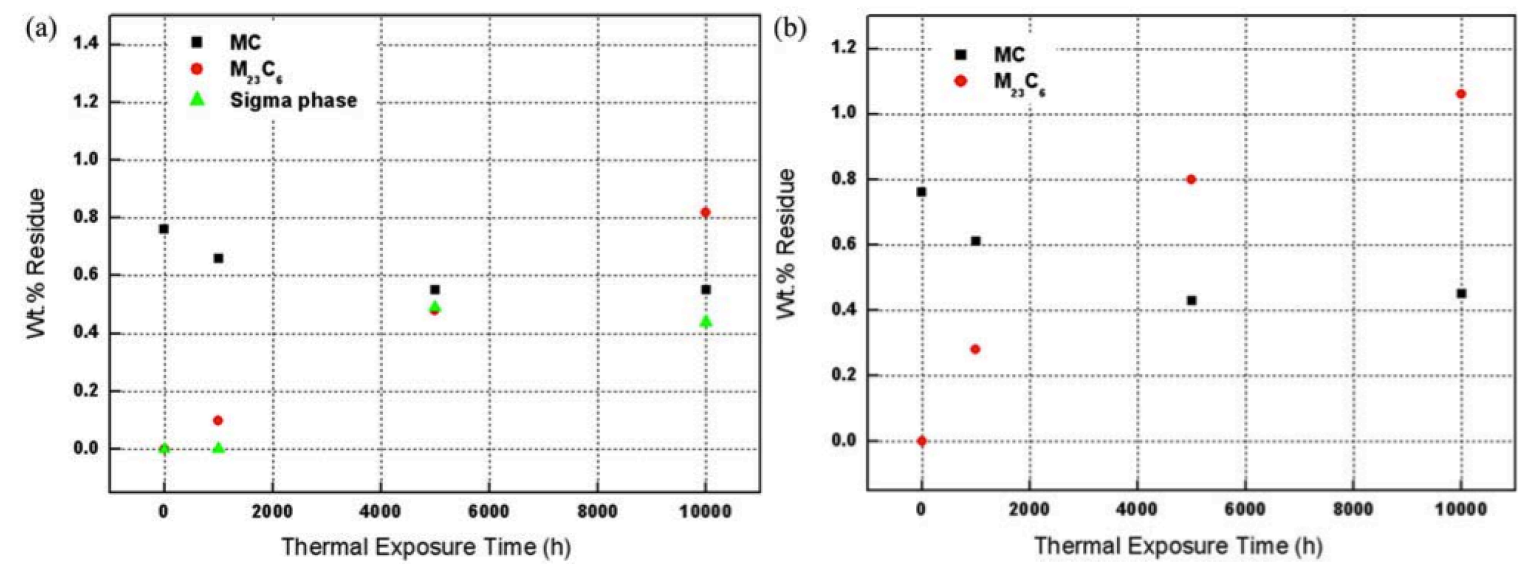

Fig. 4. Wt.\% of carbides and $\sigma$ phase in GTD-11 after thermal exposure at (a) $871^{\circ} \mathrm{C}$ and (b) $982^{\circ} \mathrm{C} .{ }^{48}$ Reproduced with permission from Springer.

Two effects of MC carbides have been observed, the first of which is that TCP phases form preferentially in the vicinity of MC carbides. ${ }^{45,46,48-50}$ This is due to higher concentrations of refractory elements that have been rejected into the matrix adjacent to these carbides. This effect has been illustrated in a modified version of the single crystal alloy RR2072 in Fig. 5.50 The second is that eta, which is enriched in $\mathrm{Ta}$ and $\mathrm{Ti}$, can form following decomposition of $\mathrm{MC}$ carbides to $\mathrm{M}_{23} \mathrm{C}_{6}$, following the equation below, due to local enrichment of these elements which are rejected from the $\mathrm{M}_{23} \mathrm{C}_{6}$ carbide. ${ }^{48,51,52}$

$$
M C+\gamma \rightarrow M_{23} C_{6}+\gamma^{\prime}
$$

(a)

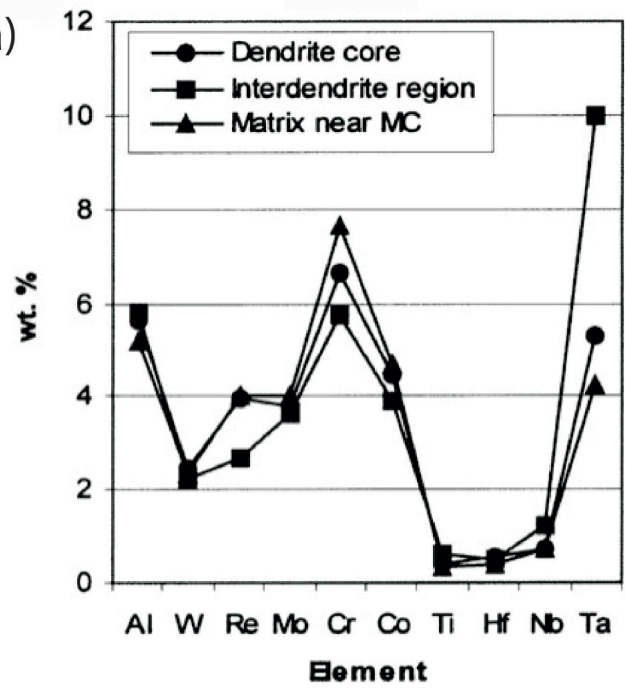

(b)

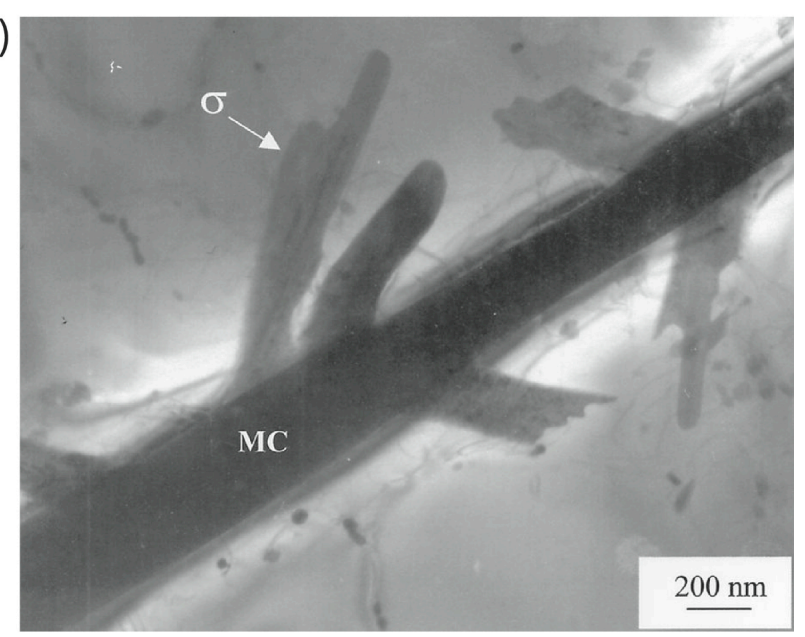

Fig. 5. (a) Average compositions of different regions after solution treatment measured by EDS on FEGSEM, (b) $\sigma$ plates adjacent to an MC carbide after exposure of same alloy at $950^{\circ} \mathrm{C}$ for 100 hours. ${ }^{50}$ Reproduced with permission from Elsevier.

In addition, relationships between carbide and TCP crystal structures have been 
proposed to affect the nucleation of TCP phases. $\sigma$ has a crystal structure closely related to that of $\mathrm{M}_{23} \mathrm{C}_{6}$ and, as a result, Sims ${ }^{53}$ stated that $\sigma$ often nucleates on $\mathrm{M}_{23} \mathrm{C}_{6}$. However, despite frequent repetition of the existence of this nucleation relationship ${ }^{47}$, no convincing evidence has yet been presented. In fact, Chen and Knowles ${ }^{45}$ observed that they were unable to find any evidence for this relationship in their alloys. Yang et al. ${ }^{21}$ alternatively proposed a nucleation relationship between $\sigma$ and $\mathrm{M}_{6} \mathrm{C}$ carbides with precipitation of needles and sheets of $\sigma$ adjacent to $\mathrm{M}_{6} \mathrm{C}$ carbides.

A similar structural relationship to that of $\sigma$ and $\mathrm{M}_{23} \mathrm{C}_{6}$ is seen between $\mu$ and $\mathrm{M}_{6} \mathrm{C}$ carbides and thus, $\mu$ is expected to precipitate preferentially in alloys that form $\mathrm{M}_{6} \mathrm{C}$ carbides. ${ }^{53}$ Precipitation of $\mu$ at $\mathrm{M}_{6} \mathrm{C}$ carbides has been observed at high temperatures, although there can also be competition between these phases for refractory elements such as $\mathrm{W}$ and Mo. ${ }^{21}$

B: Literature on the effect of B on TCP phase precipitation is very limited. Miao et al. ${ }^{54}$ observed that additions of $\mathrm{P}$ and $\mathrm{B}$ promoted the formation of Laves phase during solidification of IN718, alongside a B-containing phase. In contrast, Yu et al. ${ }^{55}$ observed that addition of $\mathrm{B}$ promoted the formation of a $\mathrm{Nb}$-containing boride phase at the expense of Laves phase. Further work is required in this area to clarify the interaction between the formation of Laves phase and borides and to investigate whether any significant effect of B content on the precipitation of other TCP phases exists.

Fe and Si: Increasing the Fe and Si content was shown by Schirra et al..$^{56}$ to promote the formation of Laves phase in IN718. The effect of the individual elements could not be separated but the Laves phase was enriched in Si compared with the matrix whereas it was depleted in Fe, suggesting that Si has a direct influence on TCP phase formation whereas the effect of $\mathrm{Fe}$, if present, is indirect. An increase in Si content has also been shown by others to promote Laves phase formation ${ }^{57}$ and to result in its enrichment in the precipitates ${ }^{57,58}$. Recent work on Laves phase in steels by Isik et al. ${ }^{59,60}$ has also shown Si enrichment in Laves precipitates. In addition, precipitation of Laves phase adjacent to $\mathrm{M}_{23} \mathrm{C}_{6}$ precipitates due to local enrichment of $\mathrm{Si}$ and $\mathrm{P}$ was seen $^{60}$. It is possible that a similar mechanism could operate in Ni-base superalloys due to Si-enrichment in Laves precipitates.

\subsection{Effect of stress}

Stress has been shown to influence TCP precipitation in the nucleation, growth and coarsening stages ${ }^{61}$. The application of an external stress to an alloy during thermal exposure affects the formation of TCPs but a survey of the literature highlights opposing observations of this effect in different alloys. With regards to $\sigma$ precipitation, Hunt ${ }^{62}$ showed that for RR1000 the application of a stress during thermal exposure increased the precipitation rate, and a similar effect has been observed in other polycrystalline alloys. ${ }^{63-65}$ However, Dreshfield and Ashbrook ${ }^{66}$ and Acharya et al. ${ }^{67}$ observed the suppression of $\sigma$ formation with the application of stress for a polycrystalline and a single crystal alloy respectively. Similarly, the rate 
of formation of $\mu$, has been observed to either increase ${ }^{7}$ or decrease ${ }^{68}$ under an applied stress, or vary depending on the magnitude of the stress ${ }^{69}$. These discrepancies are significant, since the conditions experienced by turbine components in service involve a combination of high temperature and stress such that the microstructural stability of the alloy is expected to differ from that predicted by standard static thermal exposure testing. Therefore, the development of a better understanding of the mechanisms through which stress affects TCP precipitation is urgently needed so that the effects of stress during service on the precipitation of TCPs can be accurately predicted. Various mechanisms have been proposed to account for this effect including: accelerated diffusion of TCP-forming elements allowing for formation of $\sigma$ at a wider variety of $\operatorname{sites}^{7}$ and variation of internal stresses principally caused by a change in the misfit between the matrix and TCP phases ${ }^{66,69}$. The second of these could help explain why the effect of stress can be different depending on the alloy composition as the coherency stresses caused by the matrix/TCP phase misfit will be different and thus their interaction with an applied stress will change. Debate also remains over which of the stages mentioned by Sauthoff 61 stress affects most significantly for TCP precipitation. Acharya and Fuchs ${ }^{67}$ suggested that the nucleation stage is most affected because the stress level altered the number of TCP plates observed as opposed to their size or morphology.

\section{Prediction of TCP phase formation}

Various fundamental factors have been identified as determining the stability of different TCP phases and thus must be considered when predicting TCP phase formation. The first is the valence electron concentration of the individual alloying elements. This provides the basis of the Phacomp method of prediction, which involves calculating an average electron hole number, $\mathrm{N}_{\mathrm{v}}$, for the residual $\gamma$ composition taking into account the prior precipitation of $\gamma^{\prime}$ and other combinations of carbides and borides ${ }^{70-73}$. This is then compared with a critical electron vacancy number to determine whether the alloy is likely to be unstable with respect to TCP formation.

However, TCP phases are not only electronic but also geometric compounds and thus the relative atomic sizes of the component elements are also important. The alternative method of New Phacomp ${ }^{74}$ takes both electronic structure and atomic size factors into account and involves the calculation of an average energy level for the d-orbital $\left(\mathrm{M}_{\mathrm{d}}\right.$ value) for the alloy. Pyczak et al. ${ }^{75}$ provide a detailed explanation of this method, which provides better predictions than the $\mathrm{N}_{\mathrm{v}}$-method but still contains the inherent problem that a critical $\mathrm{M}_{\mathrm{d}}$-value for stability must be worked out for each new alloy composition.

The Calphad method is a different approach to the prediction of TCP formation that avoids this problem entirely. It is based on mathematical modelling of the thermodynamic properties of the multi-component system and involves the input of coefficients describing these properties from a database of lower-order systems. The prediction of stable phases at particular combinations of temperature and composition involves the minimisation of Gibbs free energy ${ }^{76}$. However, the accuracy of the predictions made using this model are dependent on the quality of 
the data available in the database and the models being used and these have been shown often to be inaccurate for TCP phases ${ }^{77}$.

Seiser et al. ${ }^{78}$ proposed the use of two-dimensional structure maps that consider electronic and geometric factors with valence electron concentration and atomic size-factor difference as the coordinates. They showed that TCP phases in binary, ternary and multicomponent systems are located in particular regions of the structure map depending on their structure type. Further work ${ }^{79,80}$ showed that this method for bulk phases is also relevant for precipitates in a multi-phase alloy, however, knowledge of the local composition of the TCP phase is required in order to apply it.

There is a large area of work modelling and predicting TCP phase formation based on fundamental factors but further discussion is beyond the scope of the current review.

\section{Mechanisms by which TCP precipitation affects the mechanical properties of Ni-based superalloys}

The mechanical properties of primary importance for discs and blades were outlined in the introduction. The precipitation of TCP phases can affect these mechanical properties by a variety of mechanisms, which are detailed in the following sections.

\subsection{Crack initiation and propagation at TCP precipitates}

The brittle nature of TCP phases frequently leads to the formation of internal cracks within plate-like precipitates when the material is under stress, see Fig. 6. However, it is not entirely clear how detrimental this is to the material's mechanical properties. During creep testing Chen et al. ${ }^{50}$ observed internal cracks in $\sigma$ plates in RR2072 single crystal alloys that did not propagate into the matrix, and Pessah et al. ${ }^{68}$ saw the same for $\mu$ plates during creep and tensile testing of single crystal MC2. However, it was later noted that some limited crack initiation at needle-like $\mu$ precipitates did occur during tertiary creep in MC2, although it more commonly occurred at interdendritic pores ${ }^{81}$. Yang et al. ${ }^{49}$ observed bending of $\mu$ precipitates rather than cracking, which appears to contradict all other reports of the brittle behaviour of TCP precipitates. However, Qin et al. ${ }^{7}$ saw $\mu$ precipitates that appeared to have bent but actually contained microcracks, so it is possible that this could also explain the previously described behaviour (see Fig. 7). 


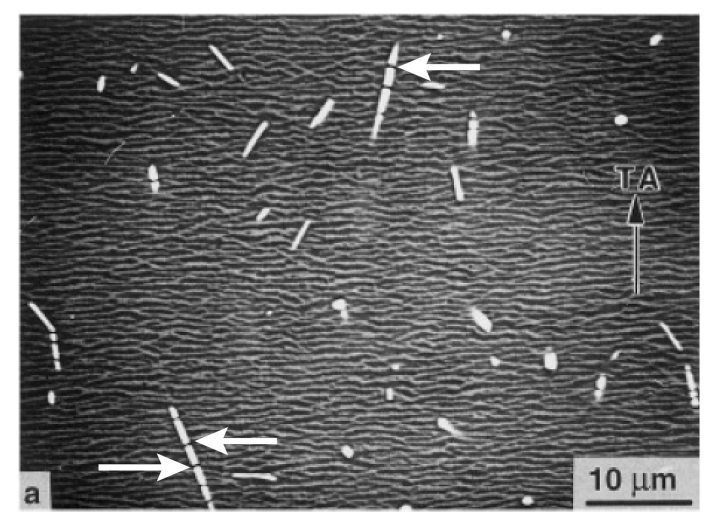

Fig. 6. Internal cracks in $\mu$ precipitates in a tensile specimen after rupture at $25^{\circ} \mathrm{C}$ (indicated by arrows). ${ }^{81}$ Reproduced with permission from Elsevier.
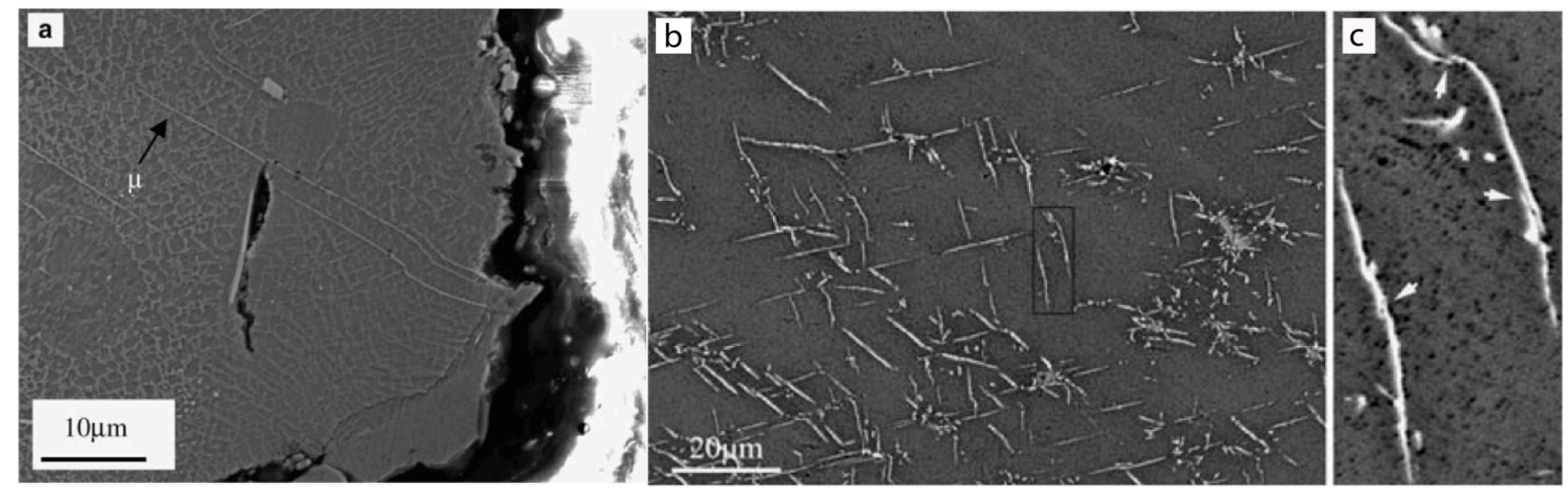

Fig. 7. (a) Bent $\mu$ precipitates in $\mathrm{K} 465^{49}$, (b) apparently bent $\mu$ precipitates in $\mathrm{K} 446$ and (c) magnified image of region of (b) in black rectangle showing microcracks in precipitates $^{7}$. Reproduced with permission from Elsevier (a) and Springer (b \& c).

In polycrystalline alloys the precipitation of TCP phases in continuous films on grain boundaries, along with carbides, can be a mechanism for loss of ductility ${ }^{82}$ and also increase of fatigue crack growth rate by providing a continuous path for crack propagation. This was observed in IN718 where fracture toughness was reduced dramatically by the precipitation of Laves phase ${ }^{56}$. It is clear that, amongst other factors, the morphology and grain boundary coverage of the TCP phase is important in determining the effect since Wang et al. ${ }^{17}$ observed that blocky $\mu$ particles on grain boundaries in a directionally solidified alloy did not reduce creep rupture life.

The positioning of the TCP phase precipitates within the microstructure also determines the type of fracture that is observed. For example, Dreshfield and Ashbrook ${ }^{66}$ observed transgranular fracture in $\sigma$-containing alloys because of intragranular $\sigma$ plates compared with intergranular fracture in $\sigma$-free alloys. This resulted in a significant reduction in room temperature UTS and loss of ductility. However, Schirra et al $^{56}$ observed intergranular fracture due to a grain boundary network of Laves phase precipitates.

Hunt et al. ${ }^{83}$ observed that precipitation of $\sigma$ at grain boundaries in RR1000 increased fatigue crack growth rates due to intergranular embrittlement. However, this effect was more dramatic for tests carried out in air than those performed in vacuum suggesting a contribution of the $\sigma$ to the intergranular oxidation mechanism 
occurring at crack tips. The exact mechanism is unknown but they proposed that $\mathrm{Cr}$ depletion effects might be responsible.

Another mechanism by which TCP phase precipitates can be involved in initiating fracture is through the formation of voids. TCP precipitation at high temperatures is often associated with void formation ${ }^{26}$, which can act as crack initiation sites. Also, increased susceptibility to creep cavitation associated with TCP precipitates during tertiary creep near to the fracture surface has been observed to contribute to failure by Hunt ${ }^{62}$ in RR1000 and Reed et al. ${ }^{84}$ in CMSX-4 (see Fig. 8).

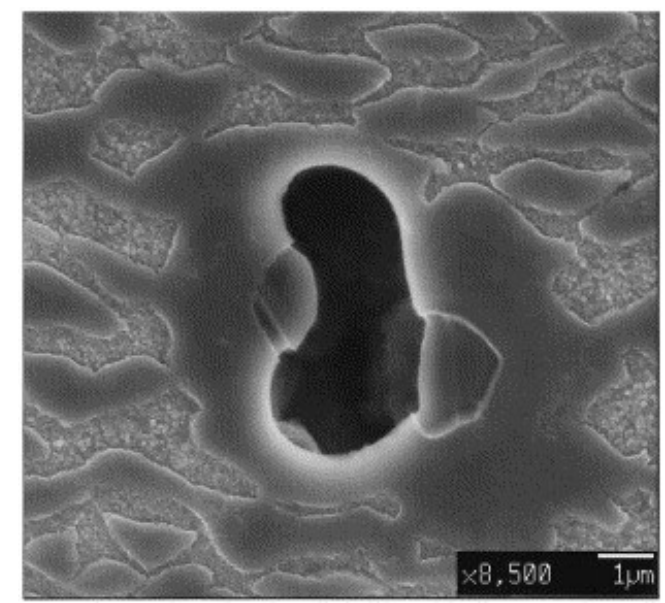

Fig. 8. Creep cavitation associated with a TCP phase precipitate in CMSX-4.84 Reproduced with permission from Elsevier.

\subsection{Depletion of refractory elements in $\gamma$ phase}

It is generally stated that one of the effects of TCP phase formation is the softening of the $\gamma$ matrix due to the removal of solid-solution strengthening refractory elements. This mechanism can reduce the yield strength of the alloy and is thought to be particularly detrimental to creep behaviour, ${ }^{81}$ hence observed loss of creep strength is frequently attributed to $\mathrm{it}^{85}$. Sims ${ }^{53}$ proposed that this mechanism is more significant when $\mu$ is precipitated as compared with $\sigma$. It is clear from the composition of TCP phases that this removal process occurs and it is the most likely mechanism to account for loss of creep strength, however, as Simonetti and Caron ${ }^{81}$ pointed out, there is a lack of conclusive evidence to prove that this is the predominant mechanism in reducing creep strength in these alloys. It is known that the depletion of refractory elements in the $\gamma$ phase to form a TCP precipitate leads to the formation of a $\gamma^{\prime}$ envelope around the precipitate $81,86,87$ but this is a localised effect rather than a more general effect on the properties of the $\gamma$ phase. The stages of this process are illustrated in Fig. 9 where the depletion of refractory elements from the vicinity of the precipitate causes the dissolution of the $\gamma$ phase such that by stage $C$ the precipitate is surrounded by a $\gamma^{\prime}$ envelope. ${ }^{87}$ 

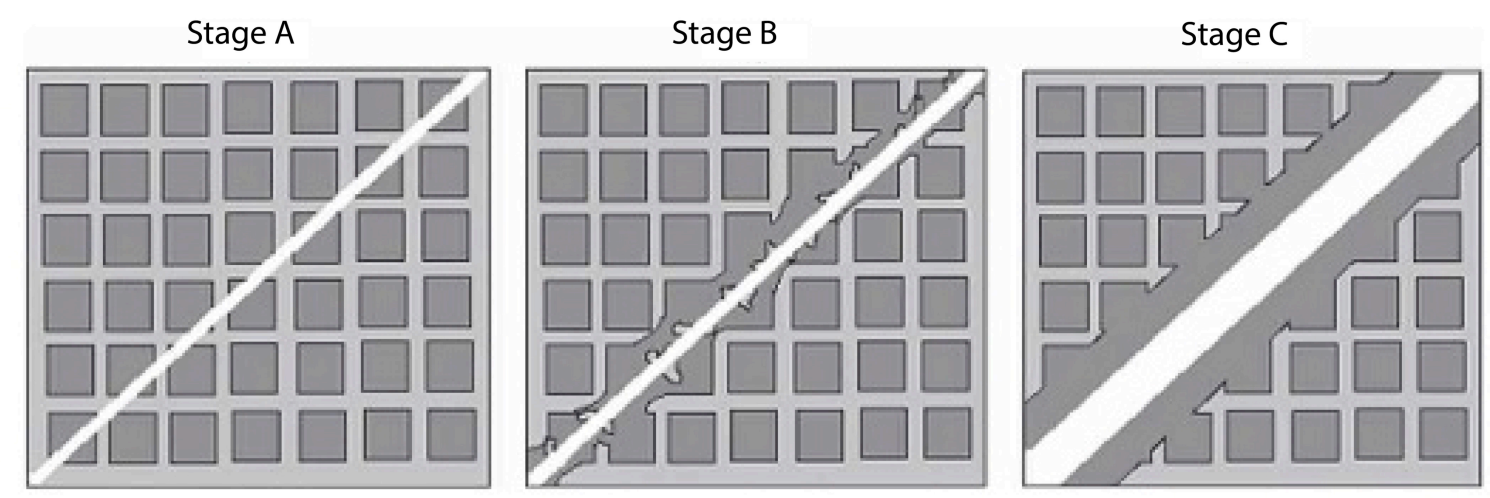

Fig. 9. Schematic diagram illustrating the formation of a $\gamma^{\prime}$ envelope adjacent to a TCP precipitate ${ }^{87}$ Reproduced with permission from Springer.

\subsection{Disruption of $\gamma / \gamma^{\prime}$ rafting behaviour}

The directional coarsening of $\gamma^{\prime}$ precipitates to form a stable $\gamma / \gamma^{\prime}$ rafted microstructure occurs during creep deformation in single-crystal Ni-base superalloys. The precipitation of TCP phases can cause local disruption of this rafted microstructure affecting the creep properties by providing easier paths for dislocation movement through their surrounding $\gamma^{\prime}$ envelopes. ${ }^{30,88}$ An example of this is the attribution by Simonetti and Caron ${ }^{81}$ of a reduction in the creep life of single crystal MC2 containing a volume fraction of more than $0.85 \% \mu$ to the disruption of the rafted microstructure. In addition, Yeh et al. ${ }^{32}$ observed accelerated coarsening of the rafted structure adjacent to the TCP precipitates and the presence of dislocations at the interface of the $\gamma^{\prime}$ envelope with the TCP precipitate, which they suggested could act as dislocation sources during deformation.

\section{Precipitate characteristics that determine the magnitude of the effect on the mechanical properties}

\subsection{Volume fraction of precipitates}

Various studies of the effect of TCP phases have concluded that the volume fraction of TCPs present in the material studied is too low for it to have an observable effect on the mechanical properties, particularly when compared with other factors. ${ }^{15,27,50}$ For example, Pessah et al. ${ }^{68}$ found no effect on fatigue or tensile properties with up to $0.5 \%$ of $\mu$ phase. This has implications for the design of new alloys as knowledge of what quantity of TCP phase can be tolerated allows the concentration of refractory elements to be increased as far as possible. 


\subsection{Precipitate morphology}

The morphology of the TCP precipitates is significant in determining the effect of the precipitates on the mechanical properties. Simonetti and Caron ${ }^{81}$ observed that the morphology of the precipitate determined the relative likelihood of internal cracking as compared to interfacial decohesion. Specifically, globular $\mu$ precipitates were shown to be more likely to exhibit interfacial decohesion and not internal cracking. Sugui et al.$^{89}$ found that both plate-like and spheroidal $\mu$ reduced the creep life. They concluded that the plate-like morphology is more harmful but do not prove this as they did not state the relative volume fractions of $\mu$ formed in each case. A plate-like or needle-like morphology is more damaging in terms of the crack initiation mechanism and therefore will particularly affect the tensile behaviour. As such, globular precipitates are expected to be less harmful as was shown by Hunt ${ }^{62}$ for globular $\sigma$ precipitates in RR1000. Crack initiation at the precipitates did not occur and the small observed decrease in tensile properties could be attributed to dissolution of the tertiary $\gamma^{\prime}$ rather than the TCP precipitates.

\section{Summary and Outlook}

The effect of a number of individual elements on the formation of TCP phases in both single-crystal and polycrystalline Ni-base superalloys has been reviewed, in particular those where debate remains. It has been concluded that the available evidence supports the promotion of TCP precipitation by a higher Co content although the mechanism for this remains unclear. However, the effects of Ru and $\mathrm{C}$ in all alloy compositions cannot be definitively concluded at this stage and there is a lack of evidence about the effect of $B$. The thermal exposure of a superalloy under an applied stress is well known to affect its susceptibility to TCP precipitation but it is clear that this effect varies with alloy composition. Various mechanisms have been proposed to account for this but further investigation is required to determine the occurrence and relative influence of these.

Various mechanisms by which TCP phase precipitation can be detrimental to the mechanical properties of an alloy have been reviewed. These include the formation and propagation of cracks at precipitates. Interestingly it has been seen that internal cracks frequently form due to the brittle nature of the TCPs but do not necessarily propagate into the matrix. The removal of refractory elements from the matrix also occurs, but there is a lack of conclusive evidence as to the size of this effect and its conseqences. Finally, TCP precipitates can disrupt the $\gamma / \gamma$ ' rafted microstructure that forms during creep deformation in single-crystal alloys.

Further work in this field is needed to establish the exact mechanisms by which some of the elements discussed affect TCP formation. This would facilitate the design of new alloy compositions that maximise the required properties at high temperatures whilst avoiding detrimental TCP precipitation. In particular, a better understanding of exactly what effect different precipitate morphologies are having on the mechanical properties and what volume fraction is required to cause detrimental effects is needed. Currently, TCP phases can often be identified during 
testing of new alloys but it is not always known whether they can be tolerated by the alloy without a detrimental effect on mechanical properties.

\section{Acknowledgements}

The author would like to thank her academic supervisor, Dr H. Stone, for advice and feedback. Funding from Rolls-Royce and the ESPRC under EP/M005607/1, $\mathrm{EP} / \mathrm{H} 022309 / 1$ and EP/H500375/1 is acknowledged. 


\section{References}

1. R. C. Reed: 'The Superalloys Fundamentals and Applications'; 2006, Cambridge University Press.

2. F. Sun and J. Zhang, Advanced Materials Research, 2011, 320, 26-32.

3. A. K. Sinha, Progress in Materials Science, 1972, 15(2), 81-185.

4. F. Long, Y. S. Yoo, C. Y. Jo, S. M. Seo, H. W. Jeong, Y. S. Song, T. Jin, and Z. Q. Hu, Journal of Alloys and Compounds, 2009, 478, 181-187.

5. C. M. F. Rae and R. C. Reed, Acta Materialia, 2001, 49(19), 4113-4125.

6. J. R. Davis: 'ASM Specialty Handbook: Heat-Resistant Materials'; 1997, ASM International.

7. X. Z. Qin, J. T. Guo, C. Yuan, G. X. Yang, L. Z. Zhou, and H. Q. Ye, Journal of Materials Science, 2009, 44(18), 4840-4847.

8. S. Tin and T. M. Pollock, Materials Science and Engineering: A, 2003, 348(1-2), 111-121.

9. T. Yokokawa, M. Osawa, K. Nishida, T. Kobayashi, Y. Koizumi, and H. Harada, Scripta Materialia, 2003, 49(10), 1041-1046.

10. R. L. Dreshfield and R. L. Ashbrook: 'Sigma phase formation and its effect on stress-rupture properties of IN-100', 1969.

11. L. Lirong, Z. Guoqing, and J. Tao, Advanced Materials Research, 2013, 634-638, 1724-1728.

12. M. Karunaratne, C. Rae, and R. C. Reed, Metallurgical and Materials Transactions A, 2001, 32(10), 2409-2421.

13. Y. Amouyal, Z. Mao, and D. N. Seidman, Acta Materialia, 2014, 74, 296-308.

14. C. Booth-Morrison, Z. Mao, R. D. Noebe, and D. N. Seidman, Applied Physics Letters, 2006, 93, 033103.

15. A. C. S Walston, R MacKay, K O'Hara, D Duhl, and R Dreshfield: 'Joint development of a fourth generation single crystal superalloy', Superalloys TMS, 2004, 15-24.

16. R. L. Dreshfield and K. J. Thomas: 'Analyses of Elemental Partitioning in Advanced Nickel-Base Superalloy Single Crystals', NASA Technical Note, 2005.

17. D. Wang, J. Zhang, and L. H. Lou, Materials Science and Engineering: A, 2010, 527(20), 5161-5166.

18. C. Cui, Y. Gu, H. Harada, and A. Sato, Metallurgical and Materials Transactions A, 2005, 36A, 2921-2927.

19. N. G. Jones, K. A. Christofidou, P. M. Mignanelli, J. P. Minshull, M. C. Hardy, and H. J. Stone, Materials Science and Technology, 2014, 30(15), 1853-1861.

20. J. Minshull: 'A1-L12 alloys based on the Al-Co-Ni-Ti quaternary system', PhD thesis, University of Cambridge, 2010.

21. J. X. Yang, Q. Zheng, X. F. Sun, H. R. Guan, and Z. Q. Hu, Materials Science and Engineering: A, 2007, 465(1-2), 100-108.

22. J. Y. Chen, Q. Feng, L. M. Cao, and Z. Q. Sun, Materials Science and Engineering: $A, 2011, \mathbf{5 2 8}, 3791-3798$.

23. Z. Shi, S. Liu, X. Wang, and J. Li, Transactions of Nonferrous Metals Society of China, 2015, 25(3), 776-782.

24. G. N. Kirby, D. L. Sponseller, and L. H. Vlack, Metallurgical Transactions, 1974, 5(6), 1477-1494. 
25. R. Darolia, D. F. Lahrman, and R. D. Field: 'Formation of Topologically Closed Packed Phases in Nickle Base Single Crystal Superalloys', Superalloys TMS, 1988, 255-264.

26. C. M. F. Rae, M. Karunaratne, C. Small, B. R. W, J. C. N, and R. C. Reed: 'Topologically close packed phases in an experimental rhenium-containing single crystal superalloy', Superalloys TMS, 2000, 767-776.

27. W. S. Walston, K. S O’Hara, E. W. Ross, T. M. Pollock, and W. H. Murphy: 'Rene N6: Third Generation Single Crystal Superalloy', Superalloys TMS, 1996, 2734.

28. S. K. O'Hara, W. S. Walston, E. W. Ross, and R. Darolia: 'Nickel base superalloy and article', Patent, US, Feb 09, 1996.

29. A. P. Ofori, C. J. Humphreys, S. Tin, and C. N. Jones: 'A TEM Study of the Effect of Platinum Group Metals in Advanced Single Crystal Nickel-Base Superalloys', Superalloys TMS, 2004, 787-794.

30. Y. Han, W. Ma, Z. Dong, S. Li, and S. Gong: 'Effect of ruthenium on microstructure and stress rupture properties of a single crystal nickel-base superalloy', Superalloys TMS, 2008, 91-97.

31. R. C. Reed, A. C. Yeh, S. Tin, S. S. Babu, and M. K. Miller, Scripta Materialia, 2004, 51(4), 327-331.

32. A. C. Yeh, C. M. F. Rae, and S. Tin: 'High Temperature Creep of Ru-Bearing NiBase Single Crystal Superalloys', Superalloys TMS, 2004, 677-685.

33. C. Y. Cui, Y. F. Gu, H. Harada, M. Osawa, and A. Sato, Metallurgical and Materials Transactions A, 2006, 37A, 355-360.

34. A. Sato, H. Harada, T. Yokokawa, T. Murakumo, Y. Koizumi, T. Kobayashi, and H. Imai, Scripta Materialia, 2006, 54(9), 1679-1684.

35. R. A. Hobbs, L. Zhang, C. M. F. Rae, and S. Tin, Metallurgical and Materials Transactions A, 2008, 39(5), 1014-1025.

36. A. Heckl, S. Neumeier, S. Cenanovic, M. Göken, and R. F. Singer, Acta Materialia, 2011, 59(17), 6563-6573.

37. K. Matuszewski, R. Rettig, M. Rasinski, K. J. Kurzydlowski, and R. F. Singer. Advanced Engineering Materials, 2014, 16, 171-175.

38. J. Y. Chen, Q. Feng, and Z. Q. Sun, Scripta Materialia, 2010, 63(8), 795-798.

39. X. Lv, J. Zhang, and Q. Feng, Journal of Alloys and Compounds, 2015, 648(C), 853-857.

40. S. Tin, T. M. Pollock, and W. T. King: 'Carbon Additions and Grain Defect Formation in High Refractory Nickel-Base Single Crystal Superalloys', Superalloys TMS, 2000, 201-210.

41. S. Tin, T. M. Pollock, and W. Murphy, Metallurgical and Materials Transactions $A, 2001,32$ A, 1743-1753.

42. X. W. Li, T. Liu, L. Wang, X. G. Liu, L. H. Lou, and J. Zhang, Materials Science and Engineering: A, 2015, 639(C), 732-738.

43. L. R. Liu, T. Jin, N. R. Zhao, Z. H. Wang, X. F. Sun, H. R. Guan, and Z. Q. Hu, Materials Letters, 2004, 58, 2290-2294.

44. K. A. Al-Jarba and G. E. Fuchs, Journal of Materials, 2004, 50-55.

45. Q. Z. Chen and D. M. Knowles, Metallurgical and Materials Transactions A, 2002, 33A, 1319-1330.

46. Y. H. Kong and Q. Z. Chen, Materials Science and Engineering: A, 2004, 366(1), 135-143.

47. P. W. Keefe, S. O. Mancuso, and G. E. Maurer: 'Effects of Heat Treatment and 
Chemistry on the Long-Term Phase Stability of a High Strength Nickel-Based Superalloy', Superalloys TMS, 1992, 487-496.

48. H.S. Lee, D.S. Kim, K.B. Yoo, and K.S. Song, Metals and Materials International, 2012, 18(2), 287-293.

49. J. X. Yang, Q. Zheng, X. F. Sun, H. R. Guan, and Z. Q. Hu, Scripta Materialia, 2006, 55(4), 331-334.

50. Q. Z. Chen, N. Jones, and D. M. Knowles, Acta Materialia, 2002, 50, 1095-1112.

51. G. Lvov, V. I. Levit, and M. J. Kaufman, Metallurgical and Materials Transactions A, 2004, 1669-1679.

52. X. Z. Qin, J. T. Guo, C. Yuan, C. L. Chen, and H. Q. Ye, Metallurgical and Materials Transactions A, 2007, 38(12), 3014-3022.

53. C. T. Sims, W. C. Hagel, and N. S. Stoloff: 'Superalloys II'; 1987, John Wiley and Sons Inc.

54. Z. J. Miao, A. D. Shan, J. Lu, and H. W. Song, Materials Science and Technology, 2012, 28(3), 334-341.

55. L. X. Yu, Y. R. Sun, W. R. Sun, W. H. Zhang, F. Liu, X. Xin, F. Qi, D. Jia, X. F. Sun, S. R. Guo, and Z. Q. Hu, Materials Science and Technology, 2013, 29(12), 14701477.

56. J. J. Schirra, R. H. Caless, and R. W. Hatala: 'The Effect of Laves Phase on the Mechanical Properties of Wrought and Cast + HIP Inconel 718', Superalloys 718, 625 and Various Derivatives, 1991, 375-388.

57. S. Guo, W. Sun, D. Lu, and Z. Hu: 'Effect of Minor Elements on Microstructure and Mechanical Properties of IN 718 Alloy', Superalloys 718, 625 and Various Derivatives, 1997, 521-530.

58. F. Yan, R. Li, J. Li, Y. Wang, C. Wang, and X. Hu, Materials Science and Engineering: $A, 2014,598,62-67$.

59. M. I. Isik, A. Kostka, G. Eggeler, Acta Materialia, 2014, 81, 230-240.

60. M. I. Isik, A. Kostka, V. A. Yardkey, K.G. Pradeep, M. J. Duarte, P. P. Choi, D. Raabe, and G. Eggeler, Acta Materialia, 2015, 90, 94-104.

61. G. Sauthoff, Journal de Physique IV, 1996, Collogue C1, 89-97.

62. D. W. Hunt: 'Stability \& mechanical properties of a nickel-base turbine disc alloy', PhD thesis, University of Cambridge, 2001.

63. C. G. B. J R Mihalisin, R T Grant, Transactions of the Metallurgical society of AIME, 1968, 242, 2399-2414.

64. R. C. Reed, M. P. Jackson, and Y. S. Na, Metallurgical and Materials Transactions A, 1999, 30A(3), 521-533.

65. J. S. Hou, L. Z. Zhou, C. Yuan, J. T. Guo, W. Wang, X. Z. Qin, and P. K. Liaw, Materials Characterization, 2013, 77(C), 47-52.

66. R. L. Dreshfield and R. L. Ashbrook: 'Further observations on the formation of sigma phase in a nickel-base superalloy (IN-100)', NASA Technical Note, 1970.

67. M. V. Acharya and G. E. Fuchs, Scripta Materialia, 2006, 54(1), 61-64.

68. M. Pessah, P. Caron, and T. Khan: 'Effect of u Phase on the Mechanical Properties of a Nickel-Base Single Crystal Superalloy', Superalloys TMS, 1992, 567-576.

69. K. Cheng, C. Jo, T. Jin, and Z. Hu, Materials Science and Engineering: A, 2011, 528(6), 2704-2710.

70. J. Boesch, and J. S. Slaney, Metal Progress, 1964, 86, 109-111.

71. L. R. Woodyatt, C. T. Sims, and H. J. Beatti Jr. Transactions of the Metallurgical 
Society of AIME, 1966, 236, 519-527.

72. W. Wallace, Metal Science, 1975, 9, 547-552.

73. R. G. Barrows, and J. B. Newkirk, Metallurgical Transactions, 1972, 3, 28892893.

74. M. Morinaga, N. Yukawa, H. Adachi, and J. Ezaki: 'New PHACOMP and Its Applications to Alloy Design', Superalloys TMS, 1984, 523-532

75. F. Pyczak, and H. Mughrabi, Intermetallics and Superalloys, 2006, 10, 523-532.

76. N. Saunders: "Phase Diagram calculations for Ni-based superalloys', Superalloys TMS, 1996, 101

77. J. C. Zhao, and M. F. Henry, Applied Technology Modeling High-Temperature Materials, 2002, 37-41.

78. B. Seiser, R. Drautz, and D. G. Pettifor, Acta Materialia, 2011, 59, 749-763.

79. J. Kossman, C.H. Zenk, I. Lopez-Galilea, S. Neumeier, A. Kostka, S. Huth, W. Theisen, M. Goken, R. Drautz, and T. Hammerschmidt, J Mater Sci, 2015, 50, 6329-6338.

80. L. Lopez-Galilea, J. Kossman, A. Kostka, R. Drautz, L. Mujica Roncery, T. Hammerschmidt, S. Huth, and W. Theisen, J Mater Sci, 2016, 51, 2653-2664.

81. M. Simonetti and P. Caron, Materials Science and Engineering: A, 1998, 254, 112.

82. H. M. Tawancy, Journal of Materials Science, 1981, 16, 2883-2889.

83. D. W. Hunt, D. K. Skelton, and D. M. Knowles; 'Microstructural stability and crack growth behaviour of a polycrystalline nickel-base superalloy', Superalloys TMS, 2000, 795-802.

84. R. C. Reed, N. Matan, D. C. Cox, M. A. Rist, and C. M. F. Rae, Acta Materialia, 1999, 47(12), 3367-3381.

85. L. Z. He, Q. Zheng, X. F. Sun, H. R. Guan, Z. Q. Hu, A. K. Tieu, C. Lu, and H. T. Zhu, Materials Science and Engineering: A, 2005, 397(1-2), 297-304.

86. C. M. F. Rae, M. S. Hook, and R. C. Reed, Materials Science and Engineering: A, 2005, 396(1-2), 231-239.

87. A. C. Yeh and S. Tin, Metallurgical and Materials Transactions A, 2006, 37A, 2621-2631.

88. R. A. MacKay: 'Morphological Changes of Gamma Prime Precipitates in NickelBase Superalloy Single Crystals', NASA Technical Memorandum 83698, 1984.

89. T. Sugui, W. Minggang, L. Tang, Q. Benjiang, and X. Jun, Materials Science and Engineering: A, 2010, 527(21-22), 5444-5451. 